\title{
ANFIS PREDICTION AND MODELLING OF HARMFUL EFFECTS ON THE ENVIRONMENT PRODUCED BY VEHICLES CROSSING ROAD BUMPS
}

\author{
SEBASTIAN TOPLAK \& DRAGO SEVER \\ Faculty of Civil Engineering, Transportation Engineering and Architecture, University of Maribor, Slovenia
}

\begin{abstract}
Modelling and predictions of road traffic emissions and ground-borne vibrations caused by vehicles driving over different types of road bumps has become a rapidly developing research area. However, due to the lack of effective methods and indicators that would define traffic behavior, the accuracy of emissions and vibrations with such an approach is often not at the appropriate level. This paper presents the attempt to model and predict harmful road traffic emissions and vibrations using microsimulation traffic tools and emission models on one side and hybrid optimized models based on artificial neural networks and neuro-fuzzy techniques on the other. The optimized ANFIS-based model was developed to predict harmful road traffic emissions. Basic data were obtained with two programs: VISSIM for micro simulation of traffic flow and ENVIVER to calculate the corresponding emissions at vehicle level. The predicted $\mathrm{NO}_{\mathrm{x}}$ values indicate a significant increase of emissions by vehicles driving over road bumps, which is almost $100 \%$ higher than normal driving. The evaluation and prediction of ground-borne vibrations focused on heavy-duty vehicles, which usually cause perceptible levels of ground-borne vibrations. The prognosis of ground-borne vibration was made with local measurements and empirical vibration predictors. The predicted vibration levels caused by heavy-duty vehicles driving over road bumps are up to 24 times higher than normal vehicle driving (sinusoidal bump). Research shows that setting up speed bumps in different locations in urban areas has to be carefully examined because the level of harmful emissions and ground-borne vibrations increase.
\end{abstract}

Keywords: traffic emissions, ground-borne vibrations, micro simulation, adaptive neuro-fuzzy inference system.

\section{INTRODUCTION}

Road transport is often an important source of air emissions and has a significant impact on air quality in urban areas. This effect increases in many cases with the use of traffic calming measures, for example with road bumps to reduce vehicle speeds. There are also problems with ground-borne vibrations caused by vehicles driving over such road obstacles [1].

Experts are often faced with the problem of how to design roads in urban areas that compromise between effective speed reductions and fewer environmental emissions, including ground-borne vibrations and noise.

The evaluation of emissions and environmental consequences caused by road traffic is an increasingly important factor in adopting transport policy decisions and the planning of transport infrastructure. The precise estimation of the expected emissions and vibrations is becoming an important challenge for the planning profession.

Road vehicle emissions depend on a number of influence factors. Emission models are used to calculate emissions from road traffic. It is possible to classify these models into several main categories according to the input data that are needed [2]. These models range from models that require only an average travel speed for emission estimates (e.g. COPERT) and models that need traffic conditions (e.g. Qualitative estimates of driving conditions "stop and go driving", "free flow driving") to express emissions (e.g. HBEFA, also in combination with VISUM). They also include traffic variable models (e.g. TEE, Matzoros model), where emission factors are defined by traffic flow variables such as average speed, 
traffic density, queue length and signal settings, as well as models which second-by-second engine or vehicle state data (e.g. VERSIT+ in combination with VISSIM) to derive emission information for the complete driving profile.

Ground-borne vibrations caused by road traffic are also a common concern of society, because they very often cause problems to individuals and structures, especially when traffic calming measures are installed in urban areas [3]. Vibrations caused by traffic represent an external source and mostly result from heavy-duty vehicles (e.g. trucks and buses). Cars and light trucks rarely cause vibrations that are discernible in buildings [4]. Road transport usually causes vibration frequency in the range between 5 and $25 \mathrm{~Hz}$ and a speed variation of soil from 0.05 to $25 \mathrm{~mm} / \mathrm{s}$ [5].

This paper presents the attempt to model and predict harmful road traffic emissions using a hybrid optimized ANFIS-based model in conjunction with a microsimulation traffic tool and emission model that in such constellation could not be traced in scientific sources.

The basic data were obtained by micro simulation of the traffic flow. Two programs were used: VISSIM to simulate traffic on the test site and to calculate velocity profiles, and VERSIT+ through ENVIVER that uses VISSIM outputs to calculate the corresponding emissions at vehicle level.

The prognosis of ground-borne vibration was based on the vibration measurements and the use of empirical laws developed by Watts and Krylov [6].

\section{EXPERIMENTAL METHOD}

Three cases of traffic calming measures were selected for the study:

(1) Trapezoidal bump (width: 5,800 mm, length: 4,900 mm, height: $100 \mathrm{~mm}$ );

(2) Trapezoidal platform (width: $6,000 \mathrm{~mm}$, length: 7,000 mm, height: $120 \mathrm{~mm}$ );

(3) Sinusoidal bump (width: 4,000 mm, length: $900 \mathrm{~mm}$, height: $50 \mathrm{~mm}$ ).

All three measures are permanently installed and located inside an urban area. The first case is located near a primary school, the other in the immediate vicinity of a kindergarten, and the third on a residential street.

The selected examples are in line with Slovenian technical guidelines and commonly used on public roads in Slovenia.

The following measurements were performed:

- $\quad$ counting of motorised traffic;

- $\quad$ vehicle speed measurements with a laser speed gun;

- $\quad$ ground vibration velocity with geophones.

Vehicle counting and speed measurements were carried out under free flow conditions on a typical weekday. The measurements of ground vibration velocity were carried out with the help of a test heavy-duty vehicle, with a constant speed of $30 \mathrm{~km} / \mathrm{h}$ over the speed bump. The mass of the heavy vehicle was 12.5 tons. The distance between the vibration measurement point and the moving vehicle was 0.8 meters.

\subsection{Emission estimation}

Simulations of different traffic situations were prepared, representing different hours from several days in a week, and the corresponding $\mathrm{NO}_{\mathrm{x}}$ emissions were estimated.

Traffic calming measures cause speed reductions consisting of a deceleration phase, a slow obstacle-driving phase, and an acceleration phase (see Fig. 1). These steps all normally result in higher fuel consumption and greater vehicle emissions than in constant driving mode. 

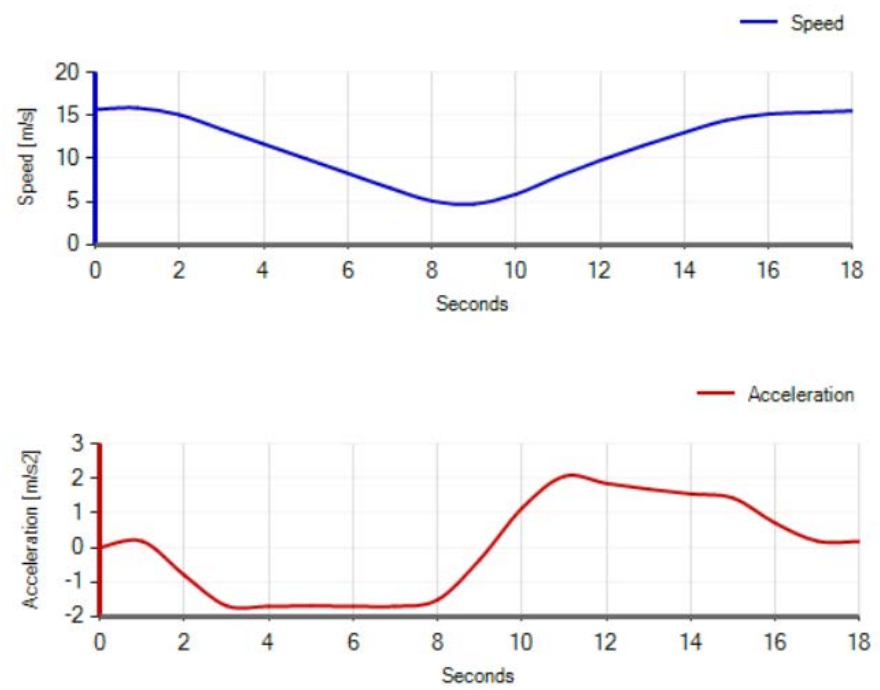

Figure 1: Vehicle speed and acceleration profile when driving over the sinusoidal speed bump.

Table 1: Simulated data for different scenarios.

\begin{tabular}{|c|c|c|c|c|c|c|c|}
\hline \multicolumn{3}{|c|}{ Input data } & \multicolumn{5}{c|}{ Output data } \\
\hline $\begin{array}{c}\text { Vehicle } \\
\text { volumes }\end{array}$ & $\begin{array}{c}\text { \% of } \\
\text { heavy } \\
\text { vehicles }\end{array}$ & $\begin{array}{c}\text { Speed } \\
\text { bump } \\
\text { type }\end{array}$ & $\begin{array}{c}\text { Average } \\
\text { speed }\end{array}$ & Acceleration & $\begin{array}{c}\text { Speed } \\
\text { difference }\end{array}$ & Headway & $\begin{array}{c}\text { Emission } \\
\text { NO }_{\mathrm{x}}(\mathrm{g})\end{array}$ \\
\hline 200 & 2 & 1 & 52.55 & 0.01 & -0.04 & 22.49 & 63.64 \\
\hline 200 & 10 & 1 & 52.55 & 0.01 & -0.04 & 22.55 & 71.36 \\
\hline 800 & 2 & 1 & 51.80 & 0.02 & -0.01 & 30.51 & 98.94 \\
\hline 800 & 10 & 1 & 51.76 & 0.02 & -0.02 & 30.59 & 109.68 \\
\hline 200 & 2 & 2 & 37.41 & 0.11 & 10.88 & 22.59 & 117.45 \\
\hline 200 & 10 & 2 & 36.91 & 0.11 & 10.48 & 22.81 & 123.73 \\
\hline 800 & 2 & 2 & 31.61 & 0.21 & 1.25 & 21.38 & 148.51 \\
\hline 800 & 10 & 2 & 29.90 & 0.22 & 0.59 & 21.11 & 156.46 \\
\hline 200 & 2 & 3 & 32.18 & 0.13 & 8.48 & 22.65 & 128.08 \\
\hline 200 & 10 & 3 & 31.26 & 0.13 & 7.81 & 22.88 & 137.62 \\
\hline 800 & 2 & 3 & 14.85 & 0.23 & -2.56 & 14.59 & 204.98 \\
\hline 800 & 10 & 3 & 14.51 & 0.22 & -2.49 & 15.08 & 228.34 \\
\hline
\end{tabular}

In the study case, we simulated two different traffic volumes $(200 / 800$ vehicles/h), two different shares of heavy vehicles $(2 / 10 \%)$ and three situations regarding traffic calming measures ( 1 - no speed bump, 2 - trapezoidal bump, 3 - sinusoidal bump). Table 1 represents the input data and the simulated output data for different scenarios. 
Output data regarding traffic flow are the speed at the end of the time step $(\mathrm{km} / \mathrm{h})$, acceleration during the time step $\left(\mathrm{m} / \mathrm{s}^{2}\right)$, speed difference relative to the preceding vehicle in the time step $(>0=$ faster in $\mathrm{km} / \mathrm{h})$ and headway - the distance to the preceding vehicle before the time step (m). All those values are average for the simulation period of 1 hour. The simulation resolution was one $\mathrm{Hz}$ with a vehicle recording step of 1 second and covered a section of a one-way urban road with a length of 260 meters.

An inverse proportion between average speed and traffic intensity can be determined based on the simulation results. In addition, we can see that the sinusoidal bump causes the most noticeable decline in speed of the traffic flow and increases $\mathrm{NO}_{\mathrm{x}}$ emissions.

\subsection{Ground-borne vibration estimation}

We measured Peak Particle Velocity (PPV) in all three orthogonal directions including maximum frequency (see Fig. 2). Typical peak vibration levels in the radial and transversal direction were small in comparison with vertical levels. Consequently, only the PPVs in the vertical direction were considered for further analysis.

Generally, the highest level of vibrations was measured during case 3 (sinusoidal bump). Values of PPV ranged from 2.9 to $4.8 \mathrm{~mm} / \mathrm{s}$, with frequencies from 20 to $23 \mathrm{~Hz}$. The second highest level of vibrations was measured during case 2 (trapezoidal platform) with values from 0.6 to $1.5 \mathrm{~mm} / \mathrm{s}$ and frequencies from 34 to $85 \mathrm{~Hz}$. The smallest PPV was measured during case 1 (trapezoidal bump) with values from 0.25 to $0.5 \mathrm{~mm} / \mathrm{s}$ and frequencies from 12 to $100 \mathrm{~Hz}$.

\section{PREDICTION AND MODELLING OF ROAD VEHICLE EMISSIONS}

\subsection{Optimization methods}

The adaptive network-based fuzzy inference system (ANFIS) is considered to be an intelligent tool utilized to understand complex problems [7]. ANFIS is being successfully used in many research areas as well as in industrial areas [8]-[11]. The most important reason for combining fuzzy systems with neural networks is to use the learning capability of neural

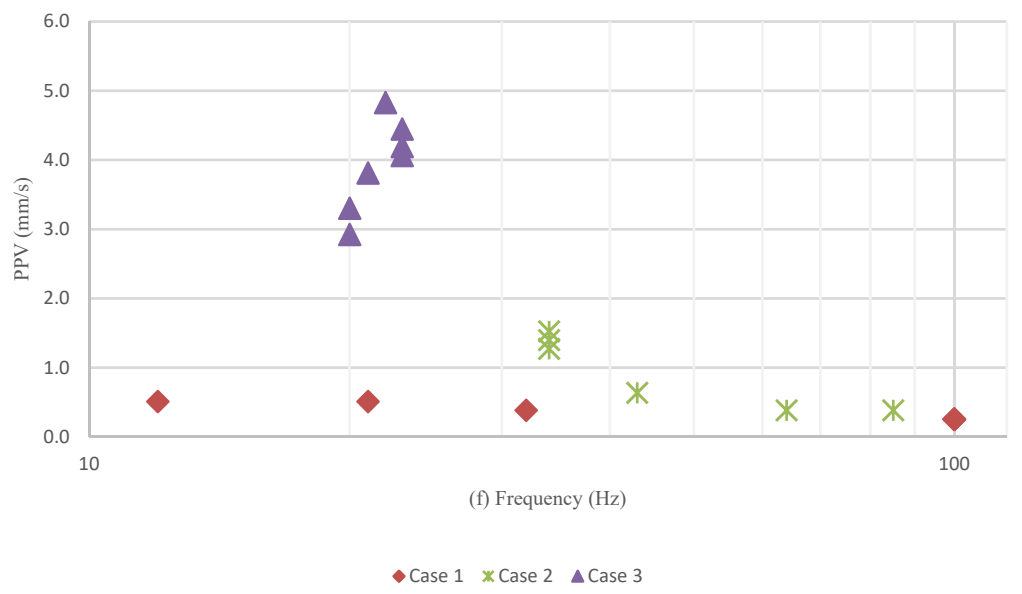

Figure 2: Results of vibration measurements at traffic calming cases. 
networks. This combination should be able to learn linguistic rules and/or membership functions (MF), or to learn how to optimize existing ones. The basic ANFIS structure for a two-input, two-rule sugeno model is presented in Fig. 3.

After the numbers of MF associated with each input were fixed, the initial values of premise parameters are set in such a way that MF are equally spaced along the operating range of each input variable. Several methods could be used to optimize the ANFIS parameters of MF. The most frequently used method contains the hybrid learning rule which combines the gradient method and the least squares estimate. However, the genetic algorithm (GA) is utilized in order to increase the convergence rate and to avoid getting trapped in local minima. In the recent past, several methods [12], [13] and algorithms have been applied to the optimization of engineering problems [14]-[19]. However in this paper the genetic algorithm is used to obtain the best prediction model for $\mathrm{NO}_{\mathrm{x}}$ emissions.

\subsection{Data set}

Training datasets contain road traffic $\mathrm{NO}_{\mathrm{x}}$ emissions in cases with speed bumps and without them. In this model, 12 emission estimations for different traffic situations were used (see Table 2). The numbers of MF associated with each input have a large influence on performance indicators. Therefore several models were built with different numbers of MF. The variables in ANFIS model are:

- $\quad$ Type of speed bump ( 1 - no speed bump, 2 - trapezoidal bump, 3 - sinusoidal bump);

- $\quad$ Different traffic volumes (vehicles/h);

- $\quad$ Different shares of heavy vehicles $(\%)$.

3.3 Comparison of the models for traffic-induced emissions

The ANFIS method is an alternative to existing methods for prediction of traffic-induced emissions. Three different models were developed:

- $\quad$ ANFIS with 2 MF associated with each input;

- $\quad$ ANFIS with $3 \mathrm{MF}$ associated with each input; and

- $\quad$ ANFIS with 4 MF associated with each input.

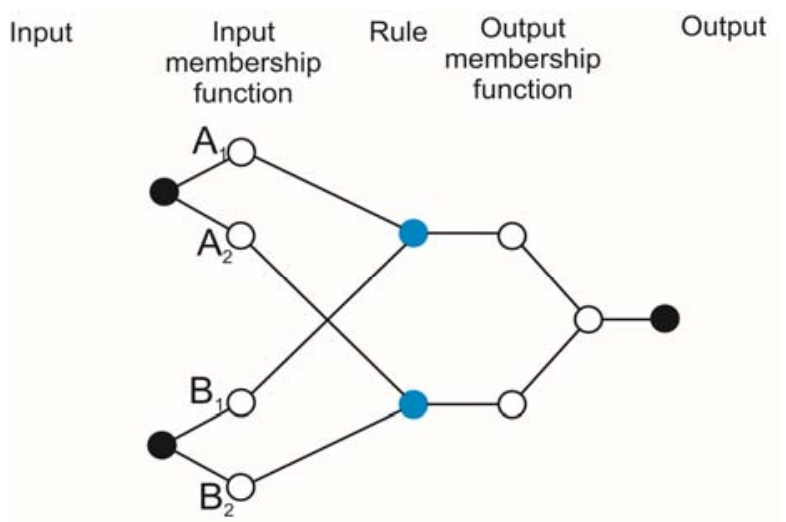

Figure 3: The basic ANFIS structure for a two-input two-rule sugeno model. 
Comparison of actual and predicted $\mathrm{NO}_{\mathrm{x}}(\mathrm{g})$ values for the ANFIS model with $3 \mathrm{MF}$ is shown in Fig. 4. The key performance indicators selected for the comparison between the actual and the predicted data are the root mean square error (RMSE) and mean of squares due to error (MSE). Table 3 shows the comparison of three different ANFIS models. It should be noted that the genetic algorithm is used to obtain the best prediction.

Table 2: Training data.

\begin{tabular}{|c|c|c|c|}
\hline $\begin{array}{c}\text { Speed bump } \\
\text { type }\end{array}$ & $\begin{array}{c}\text { Vehicle } \\
\text { volumes }\end{array}$ & $\begin{array}{c}\text { \% of heavy } \\
\text { vehicles }\end{array}$ & $\begin{array}{c}\text { Emission } \\
\mathrm{NO}_{\mathrm{x}}(\mathrm{g})\end{array}$ \\
\hline 1 & 200 & 2 & 63.64 \\
\hline 1 & 200 & 10 & 71.36 \\
\hline 1 & 800 & 2 & 98.94 \\
\hline 1 & 800 & 10 & 109.68 \\
\hline 2 & 200 & 2 & 117.45 \\
\hline 2 & 200 & 10 & 123.73 \\
\hline 2 & 800 & 2 & 148.51 \\
\hline 2 & 800 & 10 & 156.46 \\
\hline 3 & 200 & 2 & 128.08 \\
\hline 3 & 200 & 10 & 137.62 \\
\hline 3 & 800 & 2 & 204.98 \\
\hline 3 & 800 & 10 & 228.34 \\
\hline
\end{tabular}
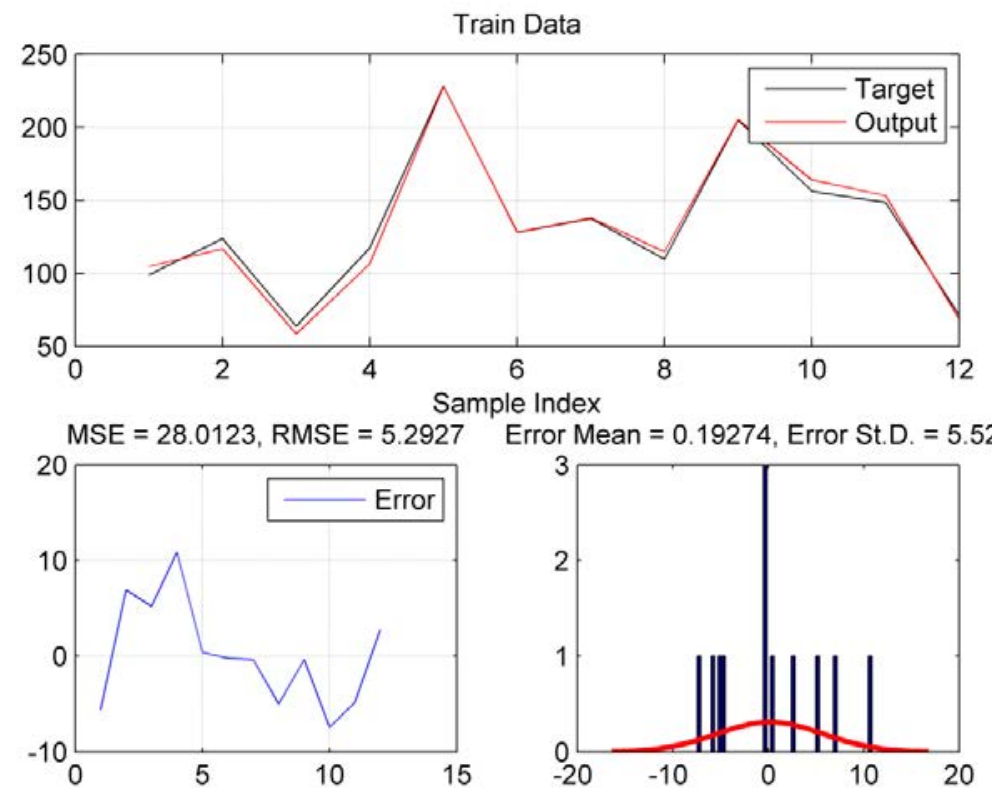

Figure 4: Comparison of actual and predicted emissions values $\mathrm{NO}_{\mathrm{x}}(\mathrm{g})$. 
Table 3: Comparison of ANFIS model with different number of MF in terms of goodness of fit.

\begin{tabular}{|c|c|c|c|}
\hline Number of MF & MSE & RMSE & Error St. D. \\
\hline $2 \mathrm{MF}$ & 103.744 & 10.1855 & 10.5003 \\
\hline $3 \mathrm{MF}$ & 28.0123 & 5.2927 & 5.5243 \\
\hline $4 \mathrm{MF}$ & 7.092 & 2.6631 & 2.7813 \\
\hline
\end{tabular}

\section{PREDICTION OF ROAD VEHICLE GROUND VIBRATIONS}

The measurements were analyzed with a model for predicting the intensity of vibration proposed by Watts [4]. For small irregularities in the road surface an empirical prediction model was developed which takes into account the local degradation of the road, the speed of the vehicle and the distance between the moving vehicle and the measuring point. The model is expressed as:

$$
P P V=0.028 \cdot a \cdot(v / 48) \cdot t \cdot p \cdot(r / 6)^{x},
$$

where $P P V=$ the peak particle velocity $(\mathrm{mm} / \mathrm{s}) ; a=$ the maximum height or depth of a localized surface defect $(\mathrm{mm}) ; v=$ the measured speed of a vehicle $(\mathrm{km} / \mathrm{h}) ; t=$ the coefficient of soil supporting a roadway structure (also ground scaling factor); $p=$ the wheel index, which is over 0.75 for heavy vehicles when one wheel crosses a damaged spot, or 1 in other cases; $r=$ the distance between the measuring point and the moving vehicle; and $x=$ the power coefficient, which determines the rate of attenuation in different soil types.

The above-mentioned model can be used for smaller sections of uneven road, which are generally lower than the road bumps. For such cases, the authors Watts and Krylov developed an additional equation on the basis of empirical measurements [6]

$$
P P V_{S}=P P V_{t} \cdot g \cdot\left(\frac{r}{6}\right)^{x}
$$

$P P V_{s}$ is the predicted PPV at the building foundation at a side, $g$ is the ground-scaling factor and $x$ is the power coefficient for the attenuation. $P P V_{t}$ is the measured test value near the obstacle or road hump.

The curves represent the predicted values of vibrations according to the type of road bump and the distance from the source of vibrations. The measured ground-borne vibrations correspond very well with the lines of the low prognostic equation. We can conclude that prognostic eqn (2) can be used for preliminary assessment of vibrations caused by heavyduty vehicles driving over road bumps.

The horizontal green line represents the limit of vibration detection by people in residential buildings and the blue line represents the level which is likely to trigger complaints from residents (BS 5228-2: 2009) [20].

The closest distance that each bump or traffic calming measure can be positioned to a residential building before there is a likelihood of perceptible vibrations or complaints from residents is determined.

The sinusoidal bump requires the largest distance between the road bump and the residential building at 12.5 meters (limit for complaints), followed by the trapezoidal platform at 2.5 meters. The trapezoidal bump does not cause such vibrations and could be placed closer to the buildings, because the limit for detecting vibrations by people in buildings are $\mathrm{PPV}=0.3 \mathrm{~mm} / \mathrm{s}$. It is therefore possible to determine that trapezoidal bumps, at least in the analysed cases, are the most suitable for the use in residential areas. 


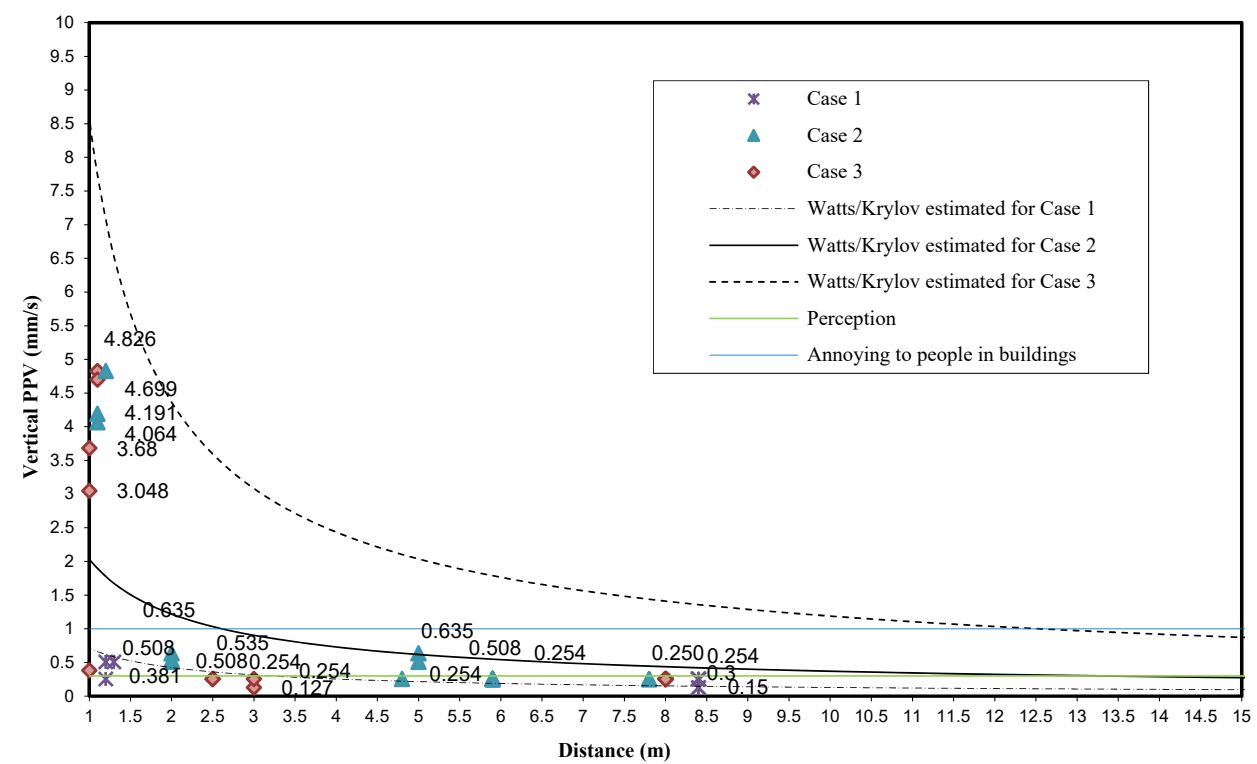

Figure 5: Predicted values (curves) of vertical PPV for all three cases.

\section{CONCLUSION}

An artificial neural network and a neuro-fuzzy technique were used for modelling the $\mathrm{NO}_{\mathrm{x}}$ emission. The accuracy and reliability of the presented model could be improved with more simulation values. It has been determined that artificial neural networks and neuro-fuzzy techniques have great potential in predicting harmful emissions from road traffic.

The prognosis of ground-borne vibrations was made with local measurements and an empirical vibration model. We found that this calculation provides a good estimate for predicting vibrations caused by heavy vehicles crossing road bumps. Based on the results it can be concluded that setting up speed bumps in urban areas dramatically increases groundborne vibrations. Although these vibrations are still below the intensity which could cause damage to buildings, they are disturbing for residents. They also contribute to environmental stressors such as noise, especially at night, which make the road area unattractive for pedestrians, cyclists and people who remain nearby.

By analyzing the predicted results of emissions and vibrations, we found that using microsimulation traffic tools and emission models on one side and hybrid optimized models based on artificial neural networks and neuro-fuzzy techniques on the other has potential in predicting harmful emissions of road traffic.

In order to improve the accuracy and reliability of the presented process, future work must be done with the aim of creating more simulation values. In addition, other microsimulation traffic tools and emission models should be used and the values obtained compared with the results of real measurements. 


\section{REFERENCES}

[1] Toplak, S., Sever, D., Ivanič, A., Moharić, M. \& Lubej, S., Effect of traffic calming measures on ground-borne vibrations in residential areas: The Slovenian experience. Proceedings of the $7^{\text {th }}$ AAAA Congress on Sound and Vibration with Exhibition, pp. 349-354, 2016.

[2] Smit, R., Ntziachristos, L. \& Boulter, P., Validation of road vehicle and traffic emission models: A review and meta-analysis. Atmospheric Environment, 44, pp. 2943-2953, 2010.

[3] Crispino, M. \& D'Apuzzo, M., Measurement and prediction of traffic induced vibrations in a heritage building. Journal of Sound and Vibration, 246(2), pp. 319335, 2001.

[4] Watts, G.R., Traffic induced vibrations in buildings. Research Report 246, Transport \& Road Research Laboratory, 1990.

[5] Hunaidi, O., Traffic Vibration in Buildings. Construction Technology Update, 39. National Research Council of Canada. Online. www.nrc-cnrc.gc.ca/ctusc/files/doc/ctu-sc/ctu-n39eng.pdf. Accessed on: 1 Mar. 2018.

[6] Watts, G.R. \& Krylov V.V., Ground-borne vibration generated by vehicles crossing road humps and speed control cushions. Applied Acoustics, 59, pp. 221-236, 2000.

[7] Jelušič, P., Soil compaction optimization with soft constrain. Journal of Intelligent and Fuzzy Systems, 29(2), pp. 955-962, 2015. DOI: 10.3233/IFS-151624.

[8] Žlender, B. \& Jelušič, P., Predicting geotechnical investigation using the knowledge based system. Advances in Fuzzy System, 2016. DOI: 10.1155/2016/4867498.

[9] Jelušič, P. \& Žlender, B., An adaptive network fuzzy inference system approach for site investigation. Geotechnical Testing Journal, 37(3), pp. 400-411, 2014. DOI: 10.1520/GTJ20120018.

[10] Žlender, B., Jelušič, P. \& Boumezerane, D., Planning geotechnical investigation using ANFIS. Geotechnical and Geological Engineering, 30(4), pp. 975-989, 2012. DOI: 10.1007/s10706-012-9520-7.

[11] Jelušič, P. \& Žlender, B., Soil-nail wall stability analysis using ANFIS. Acta Geotechnica Slovenica, 10(1), pp. 61-73, 2013.

[12] Jelušič, P. \& Žlender, B., Discrete optimization with fuzzy constraints. Symmetry (Basel), 9(6), pp. 1-22, 2017. DOI: 10.3390/sym9060087.

[13] Jelušič, P., Žlender, B. \& Dolinar, B., NLP optimization model as a failure mechanism for geosynthetic reinforced slopes subjected to pore-water pressure. International Journal of Geomechanics, 16(5), pp. 1-6, 2016. DOI: 10.1061/(ASCE)GM.19435622.0000604.

[14] Kravanja, S., Žula, T. \& Klanšek, U., Multi-parametric MINLP optimization study of a composite I beam floor system. Engineering Structures, 130, pp. 316-335, 2017. DOI: 10.1016/j.engstruct.2016.09.012.

[15] Jelusic, P. \& Kravanja, S., Optimal design of timber-concrete composite floors based on the multi-parametric MINLP optimization. Composite Structures, 179, pp. 285293, 2017. DOI: 10.1016/j.compstruct.2017.07.062.

[16] Kravanja, S., Turkalj, G., Šilih, S. \& Žula, T., Optimal design of single-story steel building structures based on parametric MINLP optimization. Journal of Constructional Steel Research, 81, pp. 86-103, 2013. DOI: 10.1016/j.jcsr.2012. 11.008 .

[17] Jelušič, P. \& Žlender, B., Optimal design of piled embankments with basal reinforcement. Geosynthetics International, pp. 1-30, 2017. DOI: 10.1680/jgein.17. 00039. 
212 High Performance and Optimum Design of Structures and Materials III

[18] Žlender, B., Jelušič, P. \& Boumezerane, D., The feasibility analysis of underground gas storage caverns. Engineering Structures, 55, pp. 16-25, 2013. DOI: 10.1016/ j.engstruct.2013.01.003.

[19] Jelušič, P. \& Žlender, B., Optimal design of pad footing based on MINLP optimization. Soils and Foundations, 2018. DOI: 10.1016/J.SANDF.2018.02.002.

[20] BS 5228-2: 2009 Code of practice for noise and vibration control construction and open sites, Part 2: Vibration, British Standards Institution, 2008. 